\title{
Properties Analysis on Travel Intensity of Land Use Patterns
}

\author{
Lishan Sun, ${ }^{1}$ Liya Yao, ${ }^{2}$ Shuwei Wang, ${ }^{1}$ Jing Qiao, $^{1}$ and Jian Rong ${ }^{1}$ \\ ${ }^{1}$ Key Laboratory of Traffic Engineering, Beijing University of Technology, 100 Pingleyuan, Chaoyang District, Beijing 100124, China \\ ${ }^{2}$ Department of Transport Engineering, Beijing Institute of Technology, 5 South Zhongguancun Street, Haidian District, \\ Beijing 100081, China
}

Correspondence should be addressed to Lishan Sun; hill310@sina.com

Received 3 December 2013; Revised 19 January 2014; Accepted 10 February 2014; Published 13 March 2014

Academic Editor: Wuhong Wang

Copyright (C) 2014 Lishan Sun et al. This is an open access article distributed under the Creative Commons Attribution License, which permits unrestricted use, distribution, and reproduction in any medium, provided the original work is properly cited.

Quantization of the relationship between travel intensity and land use patterns is still a critical problem in urban transportation planning. Achieved researches on land use patterns are restricted to macrodata such as population and area, which failed to provide detail travel information for transportation planners. There is still problem on how to reflect the relationship between transport and land use accurately. This paper presents a study that is reflective of such an effort. A data extraction method is developed to get the travel origin and destination (OD) between traffic zones based on the mobile data of 100,000 residents in Beijing. Then Point of Interests (POIs) data in typical traffic zones was analyzed combined with construction area investigation. Based on the analysis of travel OD and POI data, the average travel intensity of each land use pattern is quantified. Research results could provide a quantitative basis for the optimization of urban transportation planning.

\section{Introduction}

Due to the accelerating of urbanization, major cities in China were gradually forced to carry out high-density land development. However, excessive land development has led to rapid growth of traffic demand and aggravates the traffic congestion, air pollution, and so on.

The correlation issues between land use and travel intensity were firstly put forward by Knight [1] in 1977. Since then, a large number of scholars have conducted researches on the interaction between land use and travel behavior [2-7]. Susan [8] and Pauline et al. [9] analyzed the impact of land use on the characteristics of the trips. They pointed out that with the increasing of land use density, the number of travel would decrease. Hanssen [10] proved that land use has a profound effect on travel behavior. Silva and Luis [11] established a model to unravel the influence of land use on travel behavior. Olle et al. [12] presented a preliminary research on travel behavior analysis through mobile data.

Application of mobile data to analyze the travel characteristics has become increasingly popular in recent years, particularly since 2007. Caceres et al. [13] derived the origindestination data from mobile data. Bar-Gera [14] evaluated a cellular phone-based system for measurements of traffic speeds and travel times in Isral. Asakura and Iryo [15] analyzed the tourist behavior based on the mobile data. In Herring and his colleagues' research [16] in 2009, the mobile data were used to forecast arterial traffic through statistical learning. On this basis, other scholars have done a lot of research to expand mobile data application and travel behavior [17-22]. As one of the key area within transportation planning, research on land use properties of transport unfortunately just attracted little attention in the application of mobile data. Such applications are urgently required in urban planning of China, as most of the cities will face more and more serious traffic congestion problems generated by crowded and disordered traffic in the coming challenge years.

With the analysis and brief history above as a backdrop, it is clear that there is a close relationship between the land use and travel behavior. However, the analytic accuracy of land's traffic properties is rather low and there are difficulties in the residents' travel data acquisition. This paper describes an information technology-based procedure for analysis the traffic properties of land use. The remainder of the paper is structured as follows. Section 2 introduces the travel OD calculation based on the mobile data. Section 3 presents the 


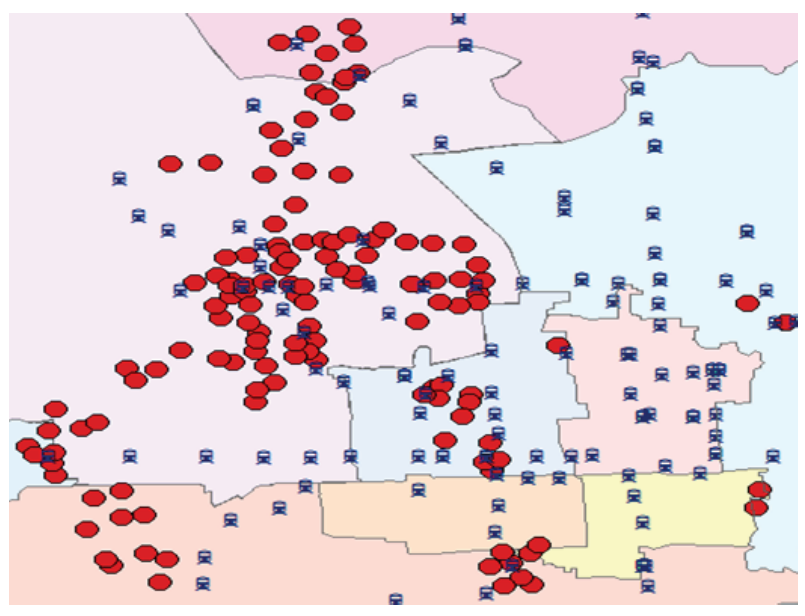

Figure 1: Mobile data on database map.

analysis of land use based on the POIs (Point of Interests). Travel intensity calculation is presented in Section 4, followed by the conclusions presented in Section 5 .

\section{Travel OD Calculation Based on the Mobile Data}

In this section, the travel OD was calculated based on 100,000 residents' mobile data of Beijing. The main steps include preprocessor of mobile data, extraction of residents' trip chain, extraction of travel OD, and sampling expansion of travel OD.

2.1. Sampling Expansion of Travel OD. In this paper, nearly 100,000 mobile users' data is extracted from Beijing Mobile. As of 2013, there are more than 31 million mobile users in Beijing, in which $72.84 \%$ belong to Beijing Mobile. The sampling expansion of travel OD coefficient should be calculated as $31000000 \times 72.84 \% / 100000=225.804$. According to the expansion coefficient, the total travel amount should be $29,786,700$, which is in line with the travel amount from Beijing Municipal Traffic Annual Report.

\subsection{Preprocessor of Mobile Data}

(a) Data Separation and Deduplication. In order to improve the validity and precision of the data, irrelevant data should be eliminated in the pretreatment stage. Generally, irrelevant data include the null value data as well as the duplicate data.

(b) Construction of Database. In order to handle the huge amount of mobile data, an appropriative database which can improve the management capability of a variety of data sources was built up. As the foundation for the following data analysis, the processed data was written to the database above, as shown in Figure 1.

(c) Mobile Data Reclassification and Sorting. After the data base construction, the mobile data of 7 days were classified into individuals, and then sorted in the ascending order of time.

2.3. Extracting Residents' Trip Chain. The trip chain data means a collection of the residents travel stops on the track in the day time. Mobile data could assist in obtaining the data of residents travel through the steps as follows.

(a) Discriminating Stagnation Point. Calculate the residence time in each cell $T$, and set the time threshold $T(T=45$ minutes, the longest bus waiting time, based on field survey). When the cell residence time $T$ is greater than $T^{\text {stay }}$, the stagnation point of the user is determined.

(b) Determining the Coverage of Base Station. The coordinates of the mobile phone base station in Beijing were obtained. On this basis, the coverage area of each mobile phone base station was determined through the principle of the Voronoi diagram. According to the coverage area of mobile phone base station and the coordinates of the point of interest, we are able to determine the affiliation of the various points of interest and mobile phone base stations.

(c) Discriminate the Home Location. The home location should be selected from the stagnation point of the user. The cross time $T^{\text {cross }}$, which is the stay period between home and stagnation point, was calculated. The user's home position is determined when the crossover time $T^{\mathrm{cross}}$ is greater than the time threshold $T^{\text {family }}$.

(d) Discrimination the Work Place Location. Similar to the method above, the workplace could also be identified from the stagnation point of the user. Regardless of the home location, the cross time $T^{\text {cross }}$, which is the stay period between work and stagnation point, was calculated. The user's work position is determined when the crossover time $T^{\text {cross }}$ is greater than the time threshold $T^{\text {work }}$.

(e) Analysis Trip Purpose. On the basis of home and work location identification, the remaining stagnation points could be mainly classified into the user's track sequence. And the trip purpose could be determined by the characteristic of interest points (culture and entertainment, live, shop, etc.), which is on the user's track and show reasonable stay period.

2.4. Extraction of Travel OD. The travel OD could be obtained from residents' day trip chain, which can be simplified to be expressed as Figure 2: A F represent the traffic zones; $a-b-c$ show a day trip chain of mobile phone user, in which $a, b$, and $\mathrm{c}$ are stagnation points, respectively.

The adjacent stagnation points which are sorted according to the time could be considered as the start and end of one trip. The traffic zone for each trip could be determined through the coordinates match between the stagnation point and the traffic zone. For example in Figure 2, a-b and b-c could be considered as two valid trips. And abelongs to zone $\mathrm{A}, \mathrm{b}$ belongs to zone $\mathrm{C}$, and $\mathrm{c}$ belongs to zone $\mathrm{E}$. Thus, we can determine one increase in the volume of the traffic count 
TABLE 1: Classification of POIs in Beijing.

\begin{tabular}{|c|c|}
\hline Major categories & Subcategories \\
\hline Guesthouse & Inns, chain inn, star hotels \\
\hline Dining & $\begin{array}{l}\text { Casual dining, Chinese fast food, western-style fast food, Japan and Korea-style fast food, west } \\
\text { restaurant, Chinese testaurant }\end{array}$ \\
\hline Leisure & Leisure square \\
\hline Companies & $\begin{array}{l}\text { Financial, transport, telecommunications company, culture media, utilities, press and } \\
\text { publication, travel agencies, factories and mines, firm, insurance company, funeral and } \\
\text { interment, securities companies, clothing and shoes, sports outdoor, training institution, } \\
\text { research institutions }\end{array}$ \\
\hline Shopping & $\begin{array}{l}\text { Electronics, audio books, electronic digital, photographic equipment, mother and children, } \\
\text { stationery, jewelry ornaments, clothing and shoes, sports outdoor, clock and optical } \\
\text { instruments, shopping mall }\end{array}$ \\
\hline Education & Preschool education, primary education, secondary education, higher education \\
\hline Transport facilities & Coach station, train station \\
\hline Tourist attractions & Heritage, scenic area, memorial hall, church, amusement parks, park, museum of art \\
\hline Living services & $\begin{array}{l}\text { Clock and optical instruments, gift and flowers, supermarket, auto services, alcohol and tea, } \\
\text { convenience, beauty salons, post office, ticket office, dry-cleaning, lottery distribution, pet, } \\
\text { bank, photographic prints, pharmacy, clinic, emergency center, epidemic }\end{array}$ \\
\hline Leisure & Stadiums, casino, KTV, massage parlors, cinema, fitness center, resort \\
\hline Medical & General hospital \\
\hline Government organization & $\begin{array}{l}\text { All level of government, organs and units, political parties and organizations, institutional } \\
\text { welfare, public security institution }\end{array}$ \\
\hline Estate plot & Cell property \\
\hline Public services & Library, palace of culture, museum, science and technology museum \\
\hline
\end{tabular}

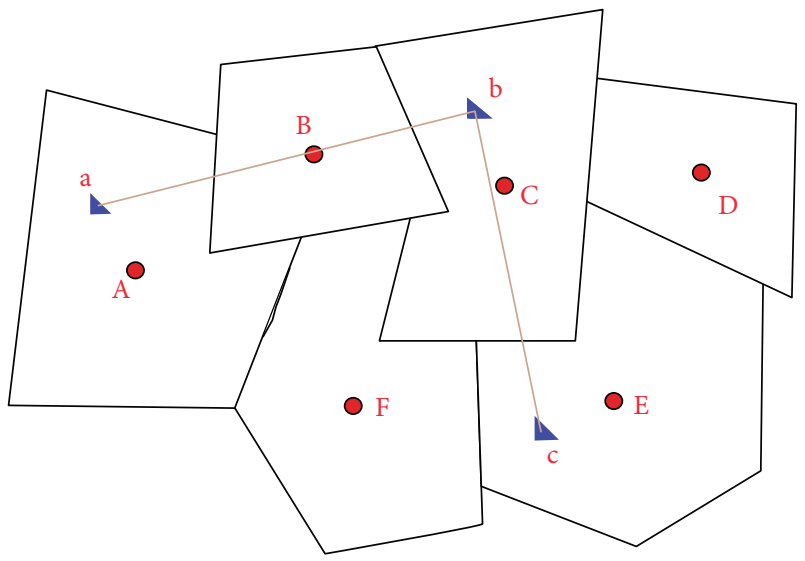

FIgURE 2: Trip chain among traffic zones.

between zone $\mathrm{A}$ and $\mathrm{C}$ and another increase between zone $\mathrm{C}$ and $\mathrm{E}$.

\section{Analysis of Land Use Based on the POIs}

POI is a phrase from the internet map search engine, for example, Baidu, youdao, and so forth. Travelers can get a lot of POIs information related to their travel purpose through internet, as shown in Figure 3. In general, POI data includes four fields: name, category, longitude, and latitude. It can not only help determine trip purpose and nature of land use but

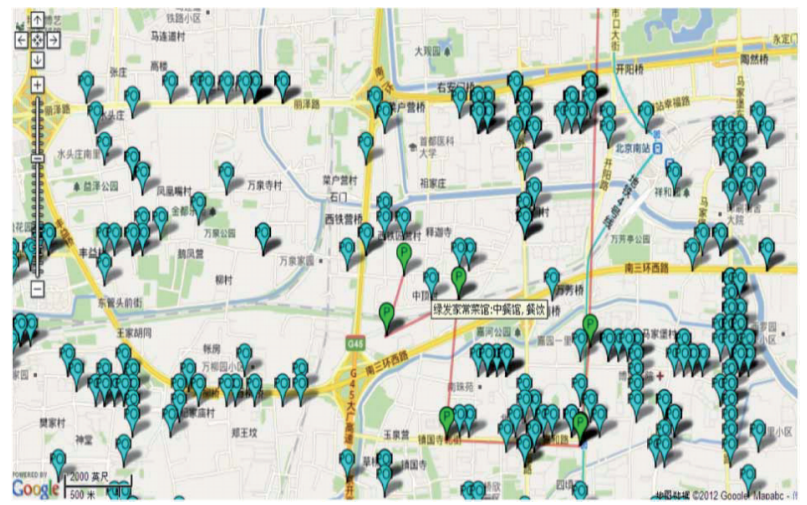

Figure 3: Distribution of POIs on web map.

also reflect distribution of population and level of economic development.

3.1. POI Extraction and Classification. POI data were extracted and divided according to the two types of major categories and subcategories, as shown in Table 1.

Combined with the "standard for classification of urban land" (GB50137-2011), the correspondence among the travel purpose, POI type, and land use type were descript as shown in Table 2. 
TABLE 2: Urban land classification based on travel purpose.

\begin{tabular}{lll}
\hline Travel purpose & POI type & Land use type \\
\hline School & Education & A3 education and research \\
Work & Companies & B2 commercial and business \\
Shopping & Shopping & B1 wholesale and commercial \\
Residential & Estate plot & R residential \\
Personal affair & Medical & A5 medical facilities \\
Leisure & Leisure & B3 recreation and sports \\
Tourist attractions & Tourist attractions & A7 heritage \\
Dining & Dining & B13 restaurant \\
\hline
\end{tabular}

TABLE 3: Construction area of educational POI.

\begin{tabular}{lcc}
\hline POI name & Land use type & Construction area $\left(\mathrm{m}^{2}\right)$ \\
\hline Dingfuzhuang Second Primary School & A3 & 1000.00 \\
Wanquan Primary School & A3 & 1580.00 \\
Beijing Cuigezhuang Primary school & A3 & 1960.00 \\
Beijing Paifang Primary school & A3 & 2243.00 \\
Seventh Primary & A3 & 2350.00 \\
Daxing District, Fifth School & A3 & 3795.00 \\
Xizhong Street Primary School & A3 & 4034.00 \\
Sigenbai Primary School & A3 & 4123.00 \\
Laogucheng Primary School & A3 & 4180.00 \\
Binhe Primary School & A3 & 4206.00 \\
Taoranting Primary School & A3 & 4776.00 \\
Nanhuzhongyuan Primary School & A3 & 5000.00 \\
\hline
\end{tabular}

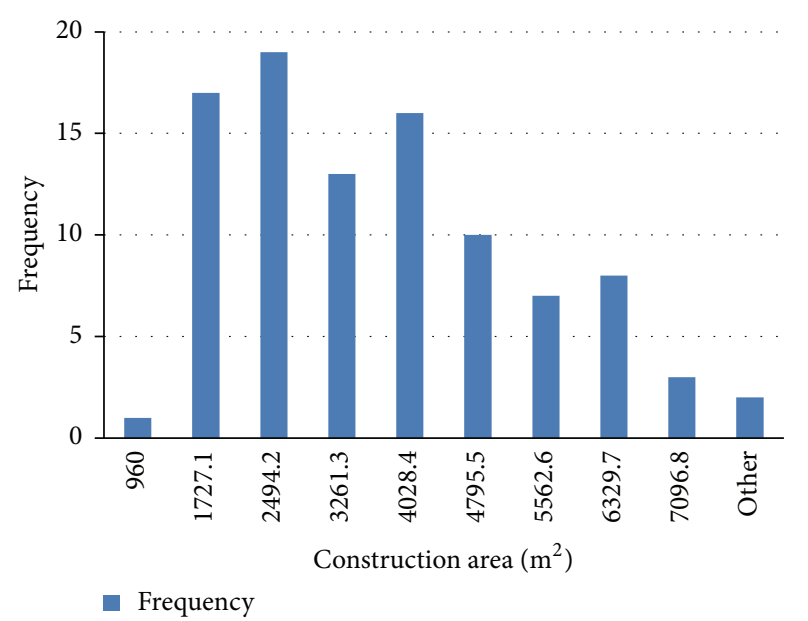

FIGURE 4: Distribution histogram of construction area for educational POI.

3.2. Construction Area of POI Investigation. Network inquiries, telephone interviews, and field inquiry were adopted in this research to obtain the average structural area for each type of land. 100 locations were selected from each type of land and the results are shown in Table 3 (education type as an example), Figures 4, 5, and 6 .

Since the selection of survey sites is random, it can be assumed that the scale of the construction area for the sample
TABLE 4: Average construction area for each pattern of POIs.

\begin{tabular}{lcccc}
\hline Land use type & Education & Medical & Tourist & Shopping \\
\hline Average construction area & 3715 & 39935 & 21812 & 68282 \\
\hline Land use type & Dining & Business & Leisure & Residents \\
\hline Average construction area & 254 & 17760 & 4478 & 158104 \\
\hline
\end{tabular}

interest points and the overall points are independent and identically distributed. The average construction area for each kind of POIs is shown in Table 4.

\section{Travel Intensity Calculation}

In order to calculate the travel intensity of each type of POI, 26 typical zones (including all kinds of POIs) were selected from within the whole city of Beijing randomly, in which 14 zones are within the second ring road, 3 within second to the third ring road, 4 within the third to the fourth ring, and 5 within the fourth to the fifth ring. Total travel times were calculated through mobile data using the method in Section 2, as shown in Table 5.

The numbers of POIs in each of the 26 traffic zones were obtained as shown in Table 6.

The construction area of different pattern land in traffic zones could be calculated according to the average construction area of each kind of POI in Table 5. Then the average 
TABLE 5: Travel times for each traffic zone.

\begin{tabular}{|c|c|c|}
\hline Traffic zone & Travel Times & Location \\
\hline Donghuashi street & 17706 & Within ring road 2 \\
\hline Wangfujin & 18743 & Within ring road 2 \\
\hline Huafushangmao & 2463 & Within ring road 2 \\
\hline Kongmiao & 5972 & Within ring road 2 \\
\hline Workers Stadium & 15871 & Within ring road 2 \\
\hline Landianchang & 31684 & Within ring road 2 \\
\hline YongdingluxiliCommunity & 15539 & Within ring road 2 \\
\hline Qinfenghuajinyuan & 7729 & Within ring road 2 \\
\hline EnjiliCommunity & 5978 & Within ring road 2 \\
\hline ShuiqinmuhuayuanCommunity & 5210 & Within ring road 2 \\
\hline Houbajia & 2061 & Within ring road 2 \\
\hline JucaiBuilding & 5644 & Within ring road 2 \\
\hline Jianguoli & 11596 & Within ring road 2 \\
\hline Jiujumingyuan & 13993 & Within ring road 2 \\
\hline University of Finance and Economics & 44379 & Ring road 2-3 \\
\hline Sanlihesanqu & 40489 & Within ring road 2 \\
\hline Guomao center 1 & 4362 & Ring road 2-3 \\
\hline Cuiweidongli & 120347 & Ring road 3-4 \\
\hline Songjiazhuang & 64163 & Ring road 3-4 \\
\hline Songyudongli & 21176 & Ring road 3-4 \\
\hline Dinghuidongli & 13504 & Ring road 3-4 \\
\hline Nanyaodi & 22896 & Ring road 4-5 \\
\hline Kuifang & 12067 & Ring road 4-5 \\
\hline Hanzhuangzidongli & 18315 & Ring road 4-5 \\
\hline National Stadium & 32547 & Ring road 4-5 \\
\hline Wudaokou & 36895 & Ring road 4-5 \\
\hline
\end{tabular}

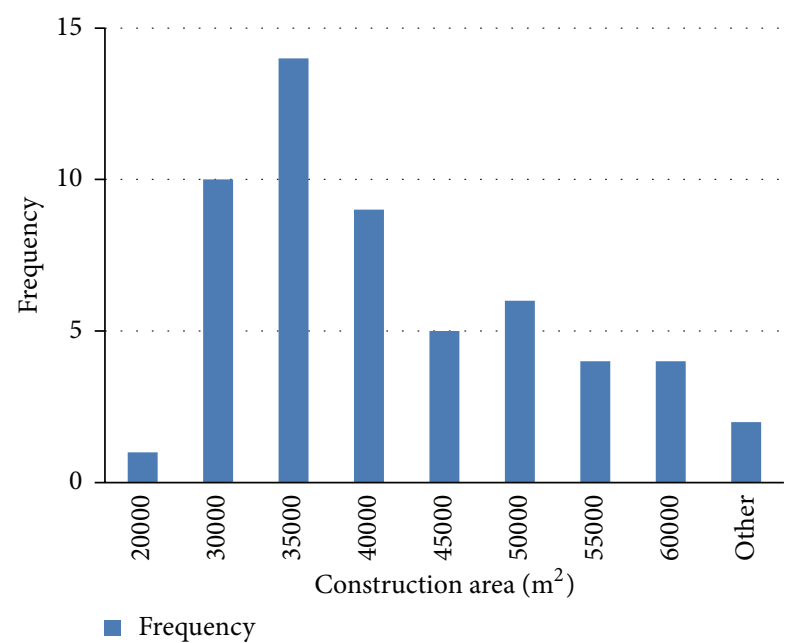

FIGURE 5: Distribution histogram of construction area for medical POI.

travel intensity could be calculated through the formula as follow:

$$
\begin{aligned}
A_{i} x_{1}+ & B_{i} x_{2}+C_{i} x_{3}+D_{i} x_{4}+E_{i} x_{5} \\
& +F_{i} x_{6}+G_{i} x_{7}+H_{i} x_{8}=P_{i}
\end{aligned}
$$

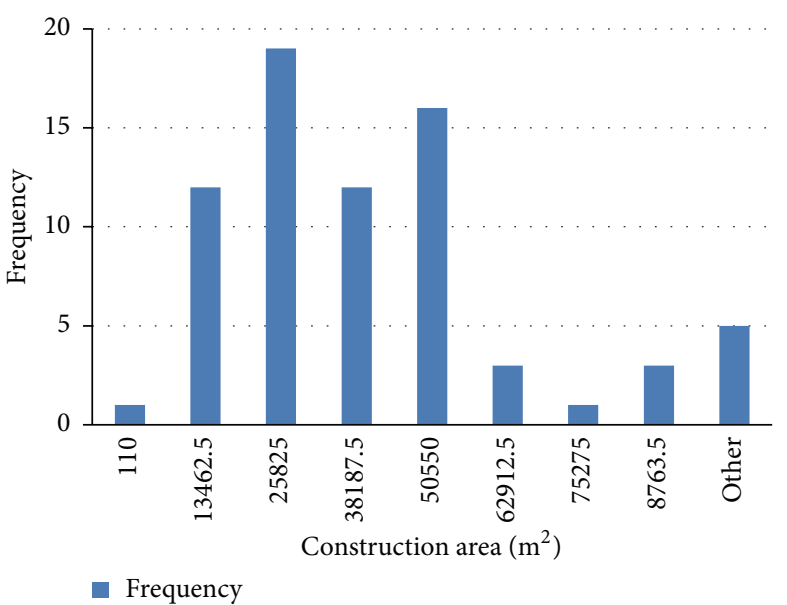

FIGURE 6: Distribution histogram of construction area for shopping POI.

where $x_{1}$ is trips per unit of land use pattern A3; $x_{2}$ is trips per unit of land use pattern A5; $x_{3}$ is trips per unit of land use pattern $\mathrm{B} 1 ; x_{4}$ is trips per unit of land use pattern $\mathrm{A} 7 ; x_{5}$ : Trips per unit of land use pattern B13; $x_{6}$ is trips per unit of land use pattern B2; $x_{7}$ is trips per unit of land use pattern B3; $x_{8}$ is trips per unit of land use pattern 
TABLE 6: The main interest point type of traffic zone.

\begin{tabular}{|c|c|c|c|c|c|c|c|c|}
\hline Traffic zone & A3 & A5 & A7 & B1 & B13 & B2 & B3 & $\mathrm{R}$ \\
\hline Nanyaodi & 0 & 1 & 1 & 0 & 0 & 5 & 4 & 1 \\
\hline Jialinhuayuan & 0 & 0 & 0 & 0 & 0 & 0 & 7 & 1 \\
\hline Kuifang & 1 & 2 & 1 & 0 & 0 & 6 & 0 & 1 \\
\hline Fanzhuangzidongli & 1 & 3 & 0 & 0 & 0 & 4 & 4 & 1 \\
\hline National Stadium & 2 & 5 & 2 & 0 & 0 & 6 & 5 & 1 \\
\hline Beijing University of Chemical Technology & 1 & 1 & 1 & 0 & 0 & 1 & 3 & 0 \\
\hline Qingyunbeili & 2 & 1 & 0 & 0 & 0 & 2 & 2 & 1 \\
\hline Cuiweidongli & 0 & 2 & 0 & 0 & 0 & 0 & 0 & 1 \\
\hline Songjiazhang & 2 & 3 & 0 & 0 & 0 & 4 & 3 & 1 \\
\hline Songyudongli & 1 & 2 & 0 & 0 & 0 & 2 & 0 & 1 \\
\hline Dinghuihuayuan & 1 & 1 & 0 & 0 & 0 & 5 & 4 & 0 \\
\hline Jindianhuayuan & 0 & 0 & 0 & 0 & 0 & 3 & 3 & 1 \\
\hline University of Finance and Economics & 0 & 1 & 0 & 0 & 0 & 4 & 0 & 1 \\
\hline Sanlihesanqu & 0 & 4 & 0 & 0 & 0 & 3 & 2 & \\
\hline QiaoJianCommunity & 0 & 0 & 0 & 0 & 0 & 5 & 0 & 1 \\
\hline PanJiaYuanNanLiCommunity & 0 & 0 & 0 & 0 & 0 & 0 & 0 & 1 \\
\hline Wangfujin & 0 & 1 & 0 & 0 & 0 & 5 & 5 & 1 \\
\hline Kongmiao & 1 & 1 & 3 & 0 & 0 & 4 & 3 & 0 \\
\hline Xinjiekouxili & 1 & 2 & 0 & 0 & 0 & 5 & 0 & 0 \\
\hline Flats of huarong & 1 & 0 & 0 & 0 & 4 & 6 & 0 & 0 \\
\hline Wudaokou & 2 & 6 & 5 & 0 & 0 & 8 & 3 & 1 \\
\hline DonghuashiStreet & 2 & 0 & 0 & 0 & 7 & 9 & 0 & 1 \\
\hline huafushangmaodalou & 2 & 0 & 0 & 0 & 1 & 1 & 0 & 0 \\
\hline YangjiayuanCommunity & 2 & 8 & 2 & 0 & 4 & 0 & 0 & 0 \\
\hline Tianshuiyuan & 0 & 2 & 0 & 0 & 2 & 2 & 2 & 1 \\
\hline Center of Guomao & 2 & 0 & 1 & 3 & 2 & 1 & 2 & 1 \\
\hline
\end{tabular}

TABLE 7: Travel intensity of each land use pattern (trips per square meter).

\begin{tabular}{lcccccccc}
\hline Land use pattern & A3 & A5 & B1 & A7 & B13 & B2 & B3 & R \\
\hline Travel intensity & 0.2154 & 0.0626 & 0.1375 & 0.1142 & 17.1181 & 0.2927 & 0.4019 & 0.0494 \\
\hline
\end{tabular}

$\mathrm{R} ; A_{i}, B_{i}, C_{i}, D_{i}, E_{i}, F_{i}, G_{i}$, and $H_{i}$ are construction area of corresponding land use patterns in traffic zone $i$; $P_{i}$ is total trips of traffic zone $i$.

The calculated travel intensity of each land use pattern is shown in Table 7.

\section{Conclusions}

As big data era approaching, the usefulness of POI data in transportation research has become more and more clear. This paper presents a research method of analyzing the relationship between travel demand and land use based on information technology. The residents' day trip chains based on mobile data were collected, and the land use characteristics were quantitative analyzed through POI data. Then the travel intensity of each type of land use patterns was obtained through the travel OD and land use characteristics, which may provide a quantitative basis for urban planner and traffic managers. Research method opens a new way of studying the relationship between urban planning and transportation, and the findings could be used as the foundation for land use decisions.

\section{Conflict of Interests}

The authors declare that there is no conflict of interests regarding the publication of this paper.

\section{Acknowledgments}

The authors wish to acknowledge the financial support for this study provided by the National Natural Science Foundation of China (nos. 51308017, 51108028), the Beijing Municipal Natural Science Foundation (no. 8122009), Beijing Nova Program, and 973 Program (no. 2012CB725403).

\section{References}

[1] R. L. Knight and L. L. Trygg, "Evidence of land use impacts of rapid transit systems," Transportation, vol. 6, no. 3, pp. 231-247, 1977. 
[2] M. Ram, C. Karthik, and C. Yichang, "Integrated land usetransport model system with dynamic time-dependent activitytravel micro simulation," Transportation Research Record, vol. 2303, pp. 19-27, 2012.

[3] M. Yegor, S. Nicolas, and W. Yinhai, "Analysis of pedestrian travel with static bluetooth sensors," Transportation Research Record, vol. 2299, pp. 137-149, 2012.

[4] T. Austin, A. Dale, and V. Brian, "Integrating a traffic router and micro simulator into a land use and travel demand model," Transportation Planning and Technology, vol. 35, no. 8, pp. 737751, 2012.

[5] K. K. W. Yim, S. C. Wong, A. Chen, C. K. Wong, and W. H. K. Lam, "A reliability-based land use and transportation optimization model," Transportation Research C, vol. 19, no. 2, pp. 351-362, 2011.

[6] J. C. Herrera, D. B. Work, R. Herring, X. Ban, Q. Jacobson, and A. M. Bayen, "Evaluation of traffic data obtained via GPSenabled mobile phones: the mobile century field experiment," Transportation Research C, vol. 18, no. 4, pp. 568-583, 2010.

[7] S. Winter and A. Kealy, "An alternative view of positioning observations from low cost sensors," Computers, Environment and Urban Systems, vol. 36, no. 2, pp. 109-117, 2012.

[8] H. Susan, How Land-Use Pattern Affect Travel Patterns: A Bibliographical Bibliography, Council of Planning Librarians, Chicago, Ill, USA, 1992.

[9] V. Pauline, A. Theo, and T. Harry, "A path analysis of social networks, telecommunication and social activity-travel Patterns," Transportation Research Part C-Emerging Technologies, vol. 26, pp. 256-268, 2013.

[10] J. U. Hanssen, "Transportation impacts of office relocation. A case study from Oslo," Journal of Transport Geography, vol. 3, no. 4, pp. 247-256, 1995.

[11] J. Silva and M. Luis, "Using a multi equation model to unravel the influence of land use patterns on travel behavior of workers in lisbon," Transportation Letters-the International Journal of Transportation Research, vol. 4, no. 4, pp. 193-209, 2012.

[12] J. Olle, A. Rein, and S. Erki, "Mobile phones in a traffic flow: a geographical perspective to evening rush hour traffic analysis using call detail records," Plos ONE, vol. 7, no. 11, 2012.

[13] N. Caceres, J. P. Wideberg, and F. G. Benitez, "Deriving origindestination data from a mobile phone network," IET Intelligent Transport Systems, vol. 1, no. 1, pp. 15-26, 2007.

[14] H. Bar-Gera, "Evaluation of a cellular phone-based system for measurements of traffic speeds and travel times: a case study from Israel," Transportation Research Part C: Emerging Technologies, vol. 15, no. 6, pp. 380-391, 2007.

[15] Y. Asakura and T. Iryo, "Analysis of tourist behaviour based on the tracking data collected using a mobile communication instrument," Transportation Research A, vol. 41, no. 7, pp. 684690, 2007.

[16] R. Herring, A. Hofleitner, S. Amin et al., "Using mobile phones to forecast arterial traffic through statistical learning," in Proceedings of the 89th Annual Meeting of the Transportation Research Board, 2009.

[17] P. Expert, T. S. Evans, V. D. Blondel, and R. Lambiotte, "Uncovering space-independent communities in spatial networks," Proceedings of the National Academy of Sciences of the United States of America, vol. 108, no. 19, pp. 7663-7668, 2011.

[18] F. Calabrese, M. Colonna, P. Lovisolo, D. Parata, and C. Ratti, "Real-time urban monitoring using cell phones: a case study in Rome," IEEE Transactions on Intelligent Transportation Systems, vol. 12, no. 1, pp. 141-151, 2011.
[19] S. Sundaram, H. N. Koutsopoulos, M. Ben-Akiva, C. Antoniou, and R. Balakrishna, "Simulation-based dynamic traffic assignment for short-term planning applications," Simulation Modelling Practice and Theory, vol. 19, no. 1, pp. 450-462, 2011.

[20] D. Shin, T. Kim, S. Kim, and D. Shin, "Design and implementation of smart driving system using context recognition system," in Proceedings of the IEEE Symposium on Computers and Informatics (ISCI '11), pp. 84-89, March 2011.

[21] W. Wang, W. Zhang, H. Guo, H. Bubb, and K. Ikeuchi, "A safetybased approaching behavioural model with various driving characteristics," Transportation Research C, vol. 19, no. 6, pp. 1202-1214, 2011.

[22] W. Wang, H. Guo, H. Bubb, and K. Ikeuchi, "Numerical simulation and analysis procedure for model-based digital driving dependability in intelligent transport system," KSCE Journal of Civil Engineering, vol. 15, no. 5, pp. 891-898, 2011. 


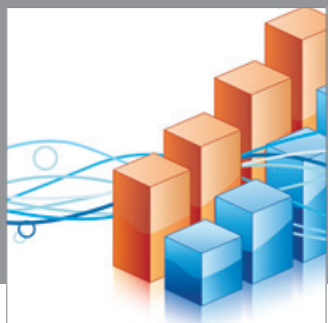

Advances in

Operations Research

mansans

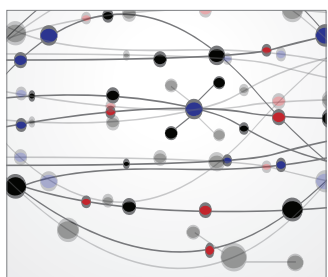

The Scientific World Journal
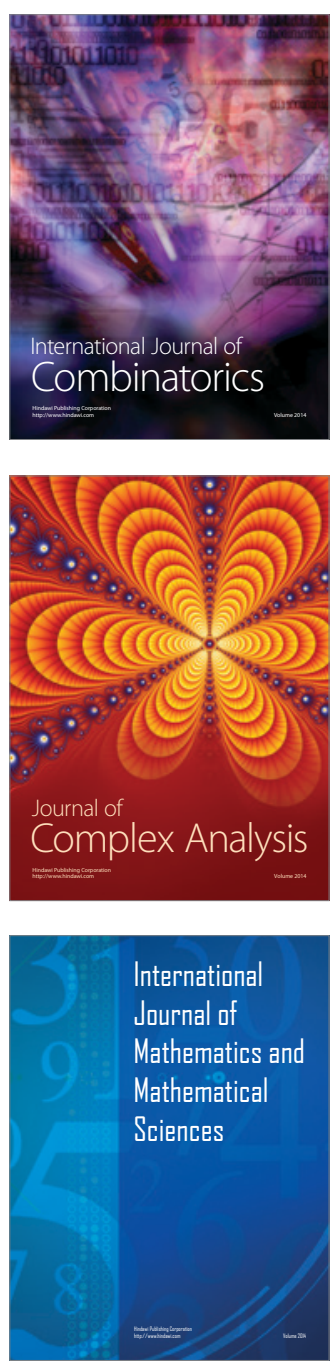
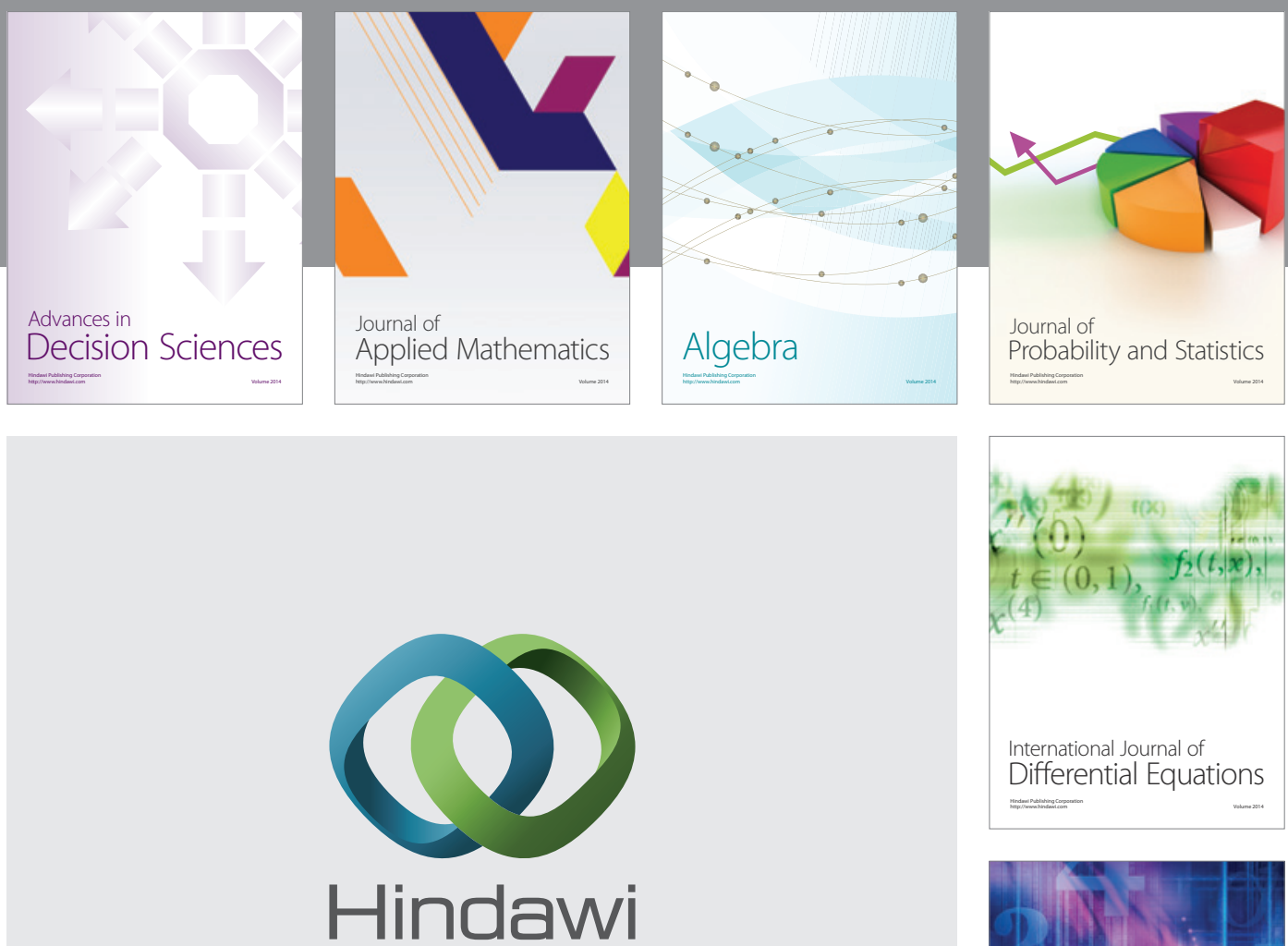

Submit your manuscripts at http://www.hindawi.com
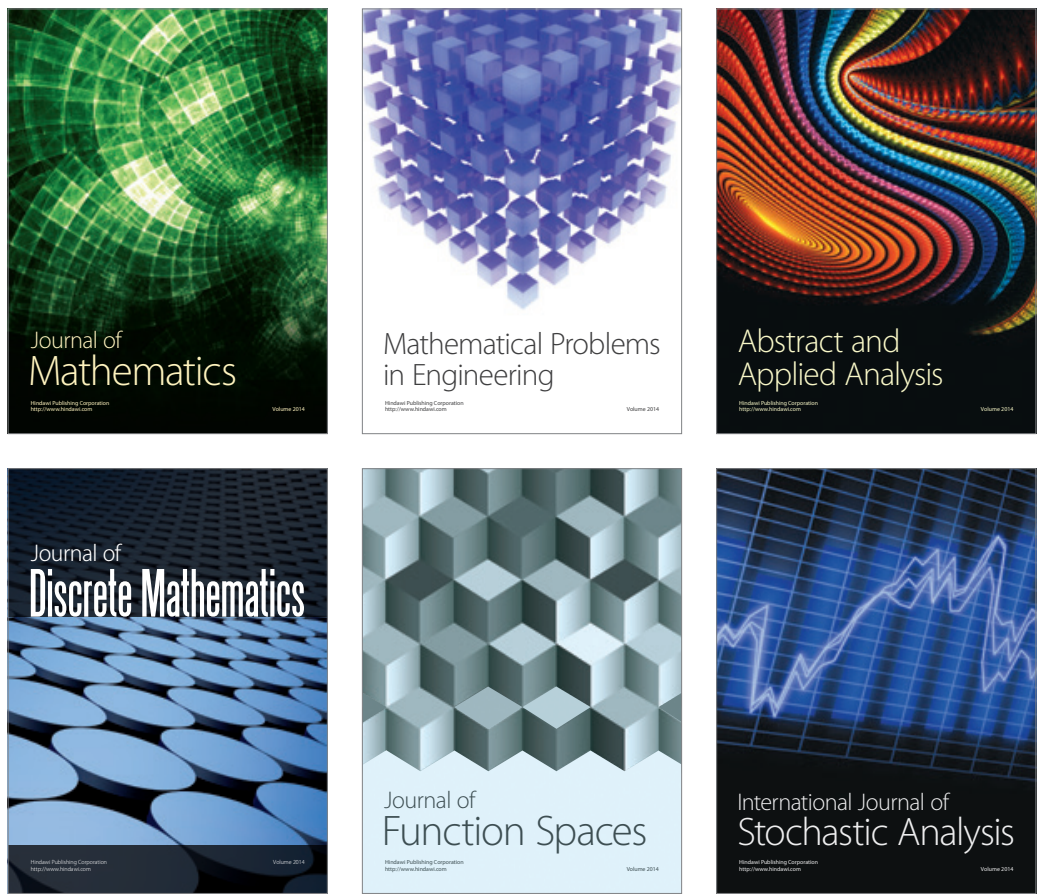

Journal of

Function Spaces

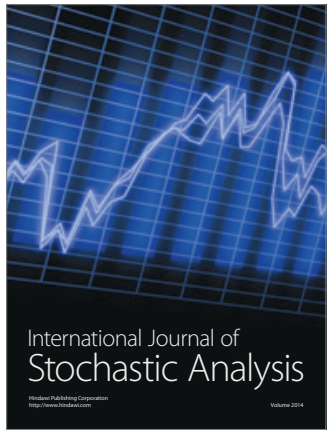

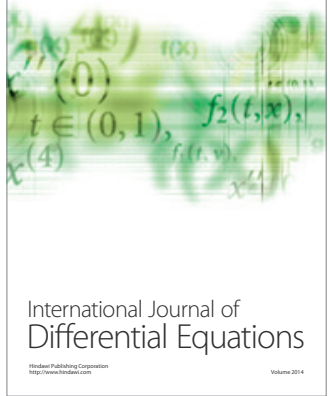
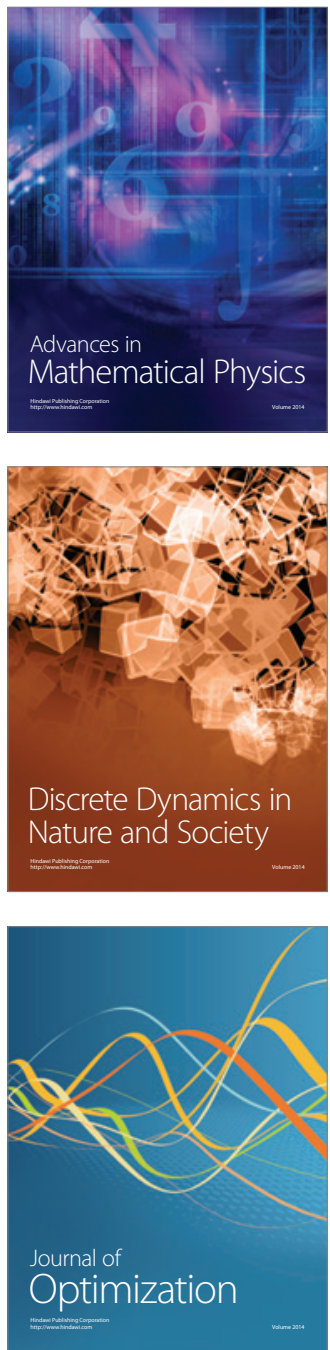